\title{
El transfondo ocultista del cuervo: desde su simbolismo poético a los topoi modernistas
}

\author{
Dolores ROMERO LÓPEZ \\ Universidad Complutense de Madrid \\ dromero@filol.ucm.es
}

Al Dr. José Paulino Ayuso, allá donde esté

\begin{abstract}
RESUMEN
El interés antropológico y religioso hacia el cuervo está presente en el budismo, en los relatos bíblicos, en la mitología nórdica, en la griega, en la leyenda artúrica y en la épica castellana. El ocultismo atribuye al cuervo la misión de guía de las almas de los muertos hacia el más allá (psicopompo). En este artículo rastreamos cómo el cuervo transfiere sus connotaciones ocultistas al símbolo poético partiendo de la valoración del poema «The Raven» de Edgar Alan Poe en su contexto cultural y estético. Charles Baudelaire y los simbolistas franceses dignifican la evolución intertextual de dicho símbolo y se la transmiten a los modernistas latinoamericanos y españoles que terminarán tipificándolo y convirtiéndolo en mero motivo recurrente. Aunque la influencia ocultista aparezca 'dispersa' en el proceso creativo, no quita su existencia. La ascendencia ocultista del cuervo explica el sentido último de algunos versos y aclara las excepciones y contradicciones que aparecen en varios poemas.
\end{abstract}

Palabras clave: cuervo, símbolo, motivo, simbolismo, modernismo, Edgar Alan Poe, Rubén Darío, modernistas españoles y latinoamericanos.

The occultist background of the raven:

From its poetic symbolism to the modernist topoi

\begin{abstract}
The anthropological and religious interest for the raven is present in Buddhism, in biblical stories, in North and Greek mythologies, in Arthurian legend and in Spanish epic. The occultism attributed to the raven the mission of guidance of dead human souls after death. This article tracks how the raven transfers its occult connotations to the poetic symbol analyzing the poem «The Raven» by Edgar Alan Poe in its cultural and aesthetic context. Charles Baudelaire and the French symbolists dignified the intertextual evolution of Poe's symbol and transferred it to Latin American and Spanish modernists. These poets used the raven not only as a symbol but mainly as a recurrent motif or poetic topos. Even though the occultist influence appears 'scattered' in the process of the creative experience of this symbol, it does not take away its existence. The occultist influence of the raven explains the ultimate meaning of some verses and clarifies the exceptions and contradictions that appear in many poems.
\end{abstract}

Keywords: , Symbol, Reason, Symbolism, Modernism, Edgar Alan Poe, Rubén Darío, Latin American and Spanish Modernists. 
SUMARIO: 1. Introducción. 2. Brote del enigma ocultista en la poesía española. 3. El cuervo: gestación del símbolo y su difusión en Europa. 4. La apropiación del símbolo: el cuervo en la poesía de Rubén Darío. 5. De la apropiación simbólica al desvío estético: la diseminación del símbolo en la poesía modernista española. 6. Conclusiones.

FECHA DE RECEPCIÓN: 14 DE 04 DE 2013 FECHA DE ACEPTACIÓN: 15 DE 05 DE 2013

\section{INTRODUCCIÓN}

La decadencia estética de finales del siglo XIX está rodeada de un halo romántico de raíz ocultista. En Europa y también en América la protesta contra el dogma de la racionalidad triunfante lleva a muchos poetas a abrazar las doctrinas de origen hermético en el contexto de una renacida visión analógica, metafórica y demoníaca del universo relacionada con el simbolismo. La materia en la que se mueve el poeta de fin de siglo -lo insólito, lo exótico, lo mítico- supone una sensibilidad especial para todo poeta que hable de misterio o de la tradición pagana heredada del romanticismo. La lengua del modernismo exalta lo sutil y lo profundo. Las doctrinas esotéricas atrajeron a los modernistas porque se aproximaban al misterio, penetraban en la sombra y buscaron en ella las claves de los enigmas de la vida, la muerte.

El gusto de los poetas modernistas por los ámbitos crepusculares o nocturnos delatan su preocupación por el más allá, por lo oculto, por las experiencias interiores y el sueño. En plena época positivista y materialista, Poe, Baudelaire, Mallarmé, Lautréamont, Bécquer, los Machado, Unamuno, Valle-Inclán, Villaespesa, Carrere y Juan Ramón Jiménez atestiguan en su crítica al mundo lo fuerte que era la tentación ocultista. El hastío de la vida expulsa a la poesía hacia el gran secreto de Hermes, el dios mensajero del más allá. Hay pocos modernistas que se escapen de esta vocación hacia lo hermético, pero es preciso comprobar si su voz poética obedece a la "moda" del misterio o a una influencia del ocultismo por convencimiento vital. La herejía estética del simbolismo ejerció una influencia clave sobre ciertos poetas; otros se limitaron a asimilar los símbolos y a presentarlos como tópicos literarios. En este artículo vamos a rastrear cómo un símbolo de origen ocultista entra en la poesía romántica norteamericana para después lucirse alegremente por la modernidad estética francesa y terminar recalando, a veces como simple influencia y otras como parodia, en el modernismo hispánico.

\section{BROTE DEL ENIGMA OCULTISTA EN LA POESÍA ESPAÑOLA}

En la mitología griega Hermes actuaba como psicopompo, guía de los difuntos, ayudándoles a encontrar el camino hacia el más allá. En la Iliada aparecen los dioses alados Hipnos (Sueño) y Tánatos (Muerte) sacando el cuerpo de Sarpedón de la batalla durante la Guerra de Troya. Según Homero, Psique, la divinidad griega que perso- 
nifica al alma, sale volando de la boca del que muere como si fuera una mariposa, asentando así la idea de que el alma tiene alas. En la tradición hindú el pájaro representa el estado superior del ser. Esta significación del pájaro como alma es un frecuente motivo folclórico debido a la creencia de que el alma escapa volando del cuerpo después de la muerte. Se suma a su facultad transmigratoria de las aves la de ser mensajeras y buenas consejeras de los humanos. El color del pájaro modifica su primitivo significado antropológico. La doctrina simbólica tradicional dota al negro de un significado infernal, diabólico, de mal agüero. Negro es el color de las tinieblas y, por ende, de la muerte. El cuervo, pájaro negro por excelencia, se ha convertido en la representación plástica y poética de la necesidad, innata en el ser humano, por explicar qué hay más allá de la muerte. El Romanticismo decimonónico, influído por el ocultismo, es una época fértil para motivos simbólicos que germinarán con fuerza durante la Modernidad.

Cita el vate nicaragüense, Rubén Darío (1867-1916), en su «Responso a Verlaine»${ }^{1}$ :

Que si posarse quiere sobre la tumba el cuervo,

ahuyenten la negrura del pájaro protervo

el dulce canto de cristal $[\ldots]$

Ese cuervo, pájaro de mal agüero ${ }^{2}$ en la tradición hispánica, recala en la poesía modernista gracias a un complejo periplo de lecturas y relecturas. «Responso a Verlaine», homenaje el maestro francés muerto en París el 8 de enero de 1896, vería la luz meses más tarde en la edición de Prosas profanas (1896) publicada en Buenos Aires. El adjetivo 'protervos' para calificar al pájaro aparece en estos versos por tres motivos: primero porque le viene bien a la rima consonante que forma con 'cuervo', en segundo lugar porque genera una aliteración ('tumba' / 'cuervo' / 'negrura' / 'protervo') y, en último término, por su significación, relacionada con la perversión y la maldad. Rubén Darío utiliza, además, el adjetivo 'protervo'3 para calificar a los cuervos en el poema «Coloquio de los Centauros» (también en Prosas profanas), en el que Orneo comenta:

\footnotetext{
${ }^{1}$ Este poema se publica por primera vez en Prosas profanas y otros poemas en la edición de 1896. Hay dos ediciones de este libro. La primera es publicada en Buenos Aires por la Imprenta Pablo E. Coni e Hijos en 1896. Esta edición fue patrocinada por Carlos Vega Belgrano a quien Rubén Darío dedica el libro. La segunda la editó la Librería de la Vda. de C. Bouret, París-México, en 1901, con algunos poemas más: «Cosas del Cid», «Dezires, layes y canciones» y «Las Ánforas de Epicuro». Con Prosas profanas Rubén Darío pretende salir en defensa de las nuevas ideas y de la libertad del arte.

${ }^{2}$ Véase, por ejemplo, en el Cantar del Mío Çid donde afirma el juglar: «Allí piensan de aguijar, allí sueltan las riendas. / A la exida de Bivar hovieron la corneja diestra, / y entrando a Burgos hobiéronla siniestra. /Meçió mio Çid los hombros y engrameó la tiesta.» Estos versos pueden leerse al comienzo del Cantar en la tirada número 2.

${ }^{3}$ El adjetivo 'protervo', aunque raro en la lengua de hoy en día, tiene sus ocurrencias en literatura castellana desde el Cancionero de Fray Ambrosio Montesinos en 1508. Lo utilizarán escritores de reconocido prestigio como Francisco de Quevedo y Lope de Vega, Benito Jerónimo Feijoo, El Duque de Rivas, Benito Pérez Galdós, Azorín, Wenceslao Fernández Flórez hasta llegar a Luis Martín-Santos en Tiempo de silencio (1962). He podido analizar cada una de las entradas que el Corpus CORDE ofrece como ejemplos de este adjetivo en esos autores. Todos utilizan 'protervo' en su sentido culto como «perverso, obstinado en el mal». Con el mismo significado es utilizado por Rubén Darío en sus Prosas profanas, ahora íntimamente vinculado al 'cuervo'.
} 
Yo comprendo el secreto de la bestia. Malignos

Seres hay y benignos. Entre ellos se hacen signos

De bien y de mal, de odio o de amor, o de pena

O de gozo: el cuervo es malo y la torcaz es buena.

\section{Y Quirón contesta:}

Ni es la torcaz benigna, ni es el cuervo protervo:

Son formas del Enigma la paloma y el cuervo.

Quirón da de lleno en la diana al convertir a la paloma y al cuervo en símbolos del 'Enigma'. ¿A qué 'Enigma' se refiere? Hay que remitirse al Antiguo Testamento. En el Génesis, capítulo 8 y versículo 6 se narra que «al cabo de cuarenta días abrió Noé la ventana del arca que había hecho y soltó al cuervo, el cual estuvo saliendo y retornando hasta que se secaron las aguas sobre la tierra.» Desde el Génesis el cuervo se marcha al Más allá sin dejar rastro y es la paloma la que retorna al arca de Noé con una rama de olivo. La tradición evoca a la paloma como mensajera de la paz y la esperanza, del bien y del Espíritu Santo; la simbología del cuervo ha quedado relegada al lado oculto. Se alude, asimismo, al cuervo en uno de los libros proféticos del Antiguo Testamento, Sofonías. En el capítulo 2, versículo 14 se narra cómo las ciudades se llenarán de desolación y por ellas camparán los animales: «[...] tanto el pelícano como el erizo, pernoctarán entre sus capiteles. Una voz canta en la ventana, el cuervo está en el umbral [...]». El cuervo se queda en el umbral, entre la luz y la oscuridad, entre la vida y la muerte, entre la poesía y la nada. Las citas del Génesis, con el vuelo hacia el más allá, y Sofonías, representándolo como pájaro del umbral, son dos modelos para justificar la tradición culta y ocultista del significado simbólico del cuervo en la poesía de Edgar A. Poe.

Esa simbología religiosa precristiana está latente en la tradición ocultista a lo largo de los siglos, cobrando particular esplendor y difusión durante el siglo XIX gracias a Madame Blavatsky (1831-1891). La fundadora de la Asociación Teosófica publicó en septiembre de 1875 su libro Isis sin velo en el que justifica el desarrollo de las ciencias ocultas y de la magia. Será su estudio Doctrina secreta (1888) el que le dará reconocimiento definitivo. En este libro se alude a Noé y retoma el enfrentamiento entre paloma y cuervo como expresión de la dualidad entre el bien y el mal, la luz y la oscuridad. En el tomo II dedicado al simbolismo arcaico universal leemos:

Noé suelta un cuervo «negro» después del Diluvio, que es el símbolo del Pralaya Cósmico, después del cual empezó la verdadera creación o evolución de nuestra tierra y de la humanidad. Los cuervos «negros» de Odín revolotearon en derredor de la Diosa Saga, y «le hablaron en voz baja del pasado y del futuro». Ahora bien; ¿cuál es el verdadero significado de todas estas aves negras? Es que todas ellas están relacionadas con la primitiva Sabiduría, que mana de la Fuente precósmica de Todo, simbolizada por la Cabeza, el Círculo o el Huevo; y todas tienen un significado idéntico y se refieren al Hombre primordial Arquetipo, Adam 
Kadmon, el origen creador de todas las cosas, que está compuesto de la Hueste de los Poderes Cósmicos, los Dhyân Chohans Creadores, Más allá de los cuales todo es Tinieblas ${ }^{4}$.

Madame Blavatsky se cuestiona el genuino alcance de estas oscuras aves. Precisamente por su color y por su capacidad de volar las vincula con la Sabiduría plena, simbolizada en la Cabeza ${ }^{5}$. Da a entender el fragmento que el conocimiento no es completo hasta que la razón no se rinde ante lo desconocido, ante la intuición, la magia, lo oculto.

Es conocida la afloración de la Teosofía durante el Fin de Siglo ${ }^{6}$. El conocimiento simbólico teosófico entra a España gracias a Mario Roso de Luna (1872-1931) que tradujo al castellano las obras de Madame Blavatsky y también a la fundación de la revista Sophía (1893-1912) que en su primer número destaca los inicios de la Sociedad Teosófica y defiende el apostolado de la raza sajona como vehículo de las grandes ideas del pensamiento moderno. Los españoles y los latinoamericanos bebieron de esta creencia y se acercan con complacencia a la lectura de obras foráneas, anglosajonas y francesas principalmente. El ocultismo es la base del simbolismo estético y literario ${ }^{7}$. Algunas de las firmas que aparecían en Sophia eran las mismas que se distinguían en los panfletos del modernismo. Giovanni Allegra cita las rúbricas de Virito Díaz-Pérez y Rafael Urbano que dirigieron la revista teosófica, las de los hermanos González Blanco, investigadores del hermetismo y propulsores del modernismo, la de Leopoldo Lugones, uno de los más grandes poetas, quien en las páginas de Sophia defiende la doble consonancia entre las doctrinas herméticas y las simbolistas, ideas que seguro influyeron en Darío y en el Valle-Inclán que después escribiría La lámpara maravillo$s a$. La difusión del teosofismo en la España de aquellos años fue rápida tal y como lo confirma Francisco Contreras en un artículo publicado en El Nuevo Mercurio en 1907 en el que justifica que la tendencia al misticismo, al ocultismo y al refinamiento decadente se debe a que el alma de la sociedad española ha reaccionado contra el abuso del escepticismo, del cientificismo y del naturalismo. Además, hay que destacar la presencia de autores extranjeros entre los que destacan Poe, Novalis, Carlyle, Nietzsche y Maeterlinck. Por último hay que considerar las resonancias de las doctrinas sapienciales que aparecen en otras revistas de la época como Helios, Renacimiento, El Nuevo Mercurio y Prometeo y que refuerzan el estrecho parentesco entre las ideas estéticas modernistas y la visión hermética del mundo. Por ejemplo en el primer número de Helios, la revista de Juan Ramón Jiménez, se publica un manifiesto escrito por Pedro

\footnotetext{
${ }^{4}$ H. P. Blavatsky, La doctrina secreta: síntesis de la ciencia, la religión y la filosofía, Málaga, 1988, vol. II, p. 162.

${ }^{5}$ Después veremos que en «The Raven», el cuervo se posa sobre la cabeza de un busto de Palas Atenea, diosa griega de la Sabiduría.

${ }^{6}$ S. Cranston, The Extraordinary Life and Influence of Helena Blavatsky, Founder of the Modern Theosophical Movement, New York, 1993.

${ }^{7}$ G. Allegra, El reino interior. Premisas y semblanzas del modernismo en España, Milán, 1982, especialmente el capítulo sexto dedicado al trasfondo ocultista de la poesía modernista española; Idem, «La influencia del ocultismo en España», Revista de Estudios Extremeños, 1, (1991), pp. 175-208.
} 
González Blanco titulado «Génesis» en el que se defiende el poema simbólico, lleno de sentimientos inefables y cargado de conceptos universales, un lenguaje perfectamente ocultista.

Los defensores del ocultismo sintieron simpatía por el anarquismo y el ateísmo, tendencias divergentes de la moral restauracionista y cristiana, no obstante, nunca olvidaron que el evolucionismo espiritual era el principal objetivo de su teosofía. Ante la pérdida de la fe en la trascendencia religiosa del cristianismo la Modernidad no abandona lo sobrenatural sino que lo transfiere del ámbito religioso cristiano al ocultismo pagano, revitalizando en dicho proceso, una arcaica tradición de símbolos ${ }^{8}$. En este sentido Oriente (y con él el Antiguo Testamento) se convierte en el espacio de recreación de la Antigüedad espiritual europea. Oriente interesa no solo por lo exótico sino porque la vida allí conserva su remota y esencial diversidad. Así se entienden en su plenitud las «Palabras preliminares» de Rubén Darío en sus Prosas Profanas (1932: 234-235). El poeta nicaragüense reclama, para el espacio ideal poético, la sabiduría ancestral, un territorio interior, espiritual, pleno de referencias herméticas.

El esoterismo, de doctrinas secretas que se transmiten a iniciados; el ocultismo, con su magia, alquimia y astrología; y el gnosticismo, que mimetiza las creencias precristianas con las cristianas, inocularon la imaginación poética romántica. Gracias a esos códigos secretos la subjetividad del artista encuentra un espacio propicio en el que cultivar la ilusión, recrear la fantasía y proponer visiones de la eternidad. El ocultismo debe entenderse como un modo de sentir el mundo no solo como un sistema riguroso y coherente. El artista toma del ocultista la noción de inefabilidad: no puede explicar el porqué de tal fascinación, ni llega a sus últimas consecuencias, pero sabe gestar inéditas imágenes, originales símbolos. El ocultismo es el residuo de un pensamiento que serpentea desde la Antigüedad y que aparece de forma irregular en la poesía de William Blake (1757-1827), Frierdrich Hölderlin (1770-1843), Gérard de Nerval (1808-1855), Edgar A. Poe (1809-1849), Rubén Darío (1867-1916), Arthur Rimbaud (1854-1891), Rainer María Rilke (1875-1926) y Ezra Pound (1885-1972) y de tantos otros. La historia de la poesía moderna está ligada a las doctrinas herméticas de Emanuel Swedenborg ${ }^{9}$ (1668-1772) y al gnosticismo de Madame Blavatsky (1831-1891). Como ha puesto de manifiesto Inge Jonsson (1995), Swedenborg en su Tratado de las representaciones y de sus correspondencias establece una relación simbólica entre las distintas partes del cuerpo humano y el alma. Estas relaciones son denominadas correspondencias y son la raíz del símbolo moderno. El modernismo hispánico, heredero del romanticismo centroeuropeo y norteamericano y del simbolismo francés, se inició como una búsqueda de un nuevo ritmo que culmina con una innovadora visión del mundo en la que lo natural y lo sobrenatural se hermanan a través de la palabra poética. El símbolo es la raíz misma de la modernidad porque somete a prueba de su estética la diversidad cultural y la supera cuando el lector capta el cos-

\footnotetext{
${ }^{8}$ R. Cardwell, «Bohemios, raros y liliales: la complicada historia del artista finisecular», en A. Cruz Casado, ed., Bohemios, raros y olvidados, Córdoba, (2006), pp. 27-66.

${ }^{9}$ I. Jonsson, Swedenborg: explorador de la naturaleza y del espíritu. Su obra y sus seguidores. Sevilla, 1995.
} 
mopolitismo de su interpretación ${ }^{10}$.Todo esto fluye naturalmente y abre su entraña si se desglosa la evolución de uno solo de esos símbolos: el cuervo.

\section{EL CUERVO: GESTACIÓN DEL SÍMBOLO Y SU DIFUSIÓN EN EUROPA}

El poema original de Edgar A. Poe, «The Raven», fue publicado por primera vez el 29 de enero de 1845 en el diario neoyorquino Evening Mirror. El argumento de este poema es sencillo. En una fría noche de invierno un joven estudiante, sentado en un sillón decadente ve entrar a través de su ventana un cuervo dentro de su habitación. A partir de ese momento el espacio poético se divide en dos y junto a la realidad material se hace presente un espacio imaginario al que se accede a través del dolor y de la tristeza tras la muerte de la amada, Lenore. El cuervo encarna la obsesión recurrente de quien no acepta la pérdida de la amada y anuncia un mensaje aterrador del Más allá: «Nevermore». El cuervo de Poe es viejo, siniestro, feo, hosco, torvo, desmañado, lúgubre, espectral, ave de antaño y posee unos ardientes ojos. Al final, el estudiante, narrador de esta historia, lo define como «profeta, ave o demonio» ${ }^{11}$. Los ojos del cuervo son descritos como los ojos de un demonio. El estudiante se mira en ellos, como si de un espejo se tratara, y ve a través de ellos el hueco oscuro, frío, solitario y triste del Más allá. El estudiante, al observar que el pajarraco tiene voz ${ }^{12}$, le pregunta si él llegará a hallar consuelo para el mal que sufre tras la muerte de Leonora, su amada. Y el cuervo le contesta «iNunca más!». Después inquiere: «Si jamás en otra vida la doncella arrobadora a mi seno he de estrechar»... y el cuervo contesta nuevamente: «iNunca más!». El estudiante infructuosamente pretende echarlo de su habitación y le ordena que retorne a su hórrida guarida, la plutónica ribera de la noche y de la bruma.

El poema de Poe, como después lo será el de Darío, es una elegía que lamenta cómo la muerte cierra la puerta del más allá, haciéndose eco de un tópico que ya habían utilizado los clásicos grecolatinos, el 'Paraclausithyron' y los eruditos medievales, el 'Nulla est redemptio'. Ese deseo de que la poesía verdadera permanezca en el tiempo percibe al inicio del poema cuando menciona que en él se hacen eco «un montón de pintorescas y curiosas tradiciones olvidadas». Esas tradiciones se refieren a lo oculto, al Enigma al que aludía Rubén Darío. El cuervo es el mensajero ${ }^{13}$ de esa «ribera Plutónica de la noche», de Tánatos.

${ }^{10}$ J. Urrutia, «La conformación del simbolismo español», en J. Mecke, coord., Discursos del 98. Albores españoles de una modernidad europea, Madrid, (2012), pp. 313-327. Véase también el último libro de Jorge Urrutia, Hallar la búsqueda (La construcción del Simbolismo español), Valladolid-New York, Ensayos Literarios Cátedra Miguel Delibes.

${ }^{11}$ Traducción al español de Juan Antonio Pérez Bonalde para la edición de El cuervo realizada en 2009 por Manuel Caldas. Las ilustraciones de esta edición, publicada en Portugal, son las originales de Gustave Doré. Ver la traducción en pp. 10-12.

${ }^{12}$ Según Hayes Kevin en VV. AA. The Cambridge Companion to Edgar A. Poe, Cambridge, Madrid, 2007, pp. 123-25, el pájaro parlante está inspirado en Grip, el cuervo de Barnaby Rudge. A Tale of the Riots of Eighty de Charles Dickens. Poe había escrito una crítica de Barnaby Rudge para la revista Graham's Magazine argumentando, entre otras ideas, que dicho cuervo debería haber servido para un propósito más poético y simbólico.

${ }^{13}$ En la mitología nórdica los dos cuervos de Odín representan el pensamiento y la memoria. 
No es de extrañar pues, que «El cuervo» sea el germen de Filosofía de la composición, ensayo publicado solo un año después que el poema, en el que Edgar Allan Poe realiza un alegato de la inmortalidad humana a través de la defensa de la belleza absoluta y del amor sobrenatural. El poeta es el mediador del enigma y, como Virgilio en la Divina Commedia, conduce al lector hacia el mundo ideal de la belleza (mujer hermosa) y de la eternidad (alma bella). Tras la publicación de «El cuervo» y de su Filosofia, Edgar A. Poe se convirtió en un reconocido poeta de fama internacional. Paulatinamente sus lectores comenzaron a identificar al estudiante con el propio autor a quien apodaron «El cuervo». El poema fue pronto ampliamente reimpreso, plagiado y parodiado ${ }^{14}$.

Fue Léon Lemonnier ${ }^{15}$ el primero en analizar con sistematicidad la lectura que los simbolistas franceses realizaron de «El cuervo» de Edgar A. Poe. El poema parte del prosaísmo poético romántico y lo trasciende creando, lo que, en palabras de Baudelaire, constituye el primer símbolo moderno. Francisco Javier del Prado Biedma ${ }^{16}$ demuestra cómo Baudelaire descubrió a Poe en 1847. Baudelaire sintió una mezcla de admiración, morbo y compasión por la vida de Edgar A. Poe. Se sintió identificado con su espíritu inquieto, con su vida bohemia, con la dipsomanía, en su forma de entender y vivir las relaciones amorosas. Percibió que había una simbiosis entre sus extraordinarios cuentos y su propia vida y, por ello, llevó a cabo diversas traducciones que han sido estudiadas en detalle por la investigadora Belén Piqueras Cabrerizo $^{17}$. En 1848 Baudelaire publica sus Études sur Poe, donde habla de su teoría de la sorpresa, entendida como novedad, originalidad, imaginación y misterio. En 1852 Charles Baudelaire publica Edgar A. Poe, sa vie et ses ouvrages, primera versión de lo que después utilizará como prólogo a sus Histoires extraordinaires, la traducción más popular de relatos de Poe que vio la luz en 1856. La semblanza que realiza Charles Baudelaire de la vida de Poe será fundamental para expandir su fama. Al poeta francés le debemos el hecho de haber 'literaturizado' la vida de su admirado poeta. A partir de ese momento los extraordinarios cuentos de Edgar A. Poe se dispersarán por Europa -en versión francesa- acompañados por una introducción donde el poeta norteamericano era presentado como un desdichado, un ilustre desventurado, un mártir santo. Stéphane Mallarmé puso igualmente su parte y perfeccionó su inglés para leer mejor y traducir la poesía de Edgar A. Poe ${ }^{18}$.

\footnotetext{
14 VV.AA, The Cambridge Companion to Edgar A. Poe, Cambridge, Madrid, 2007. Prólogo de Montero Alonso. Edición de Kevin J. Hayes.

15 L. Lemonnier, Edgar Poe et les poètes français, París, 1932.

${ }^{16}$ F. J. Prado Biezma, «Poe, Baudelaire y Mallarmé (en el nacimiento del poema moderno)», Revista de Filología, Universidad de La Laguna, 28, (2010), pp. 95-122.

17 B. Piqueras Cabrizo, «La lírica impersonal de la urbe moderna: aproximación a Baudelaire como traductor de Edgar A. Poe», Cuadernos de Investigación Filológica, 31-32, (2012), pp.135-142. Les Poème d'Edgar Poe, en traducción de Stéphane Mallarmé con ilustraciones de Edouard Manet fue publicado en Bruxelles por E. Deman en 1888. Puede consultarse en la versión digital que se encuentra en la Biblioteca Nacional de Francia. Véase también J. J. Lanero, J. C Santoyo y S. Villoria, «50 años de traductores, críticos e imitadores de Edgar A. Poe (1857-1913)», Livius, 3, (1993), pp. 159-184.

18 E. A. Poe, Les Poème d'Edgar Poe. Bruxelles, 1888. Traducción de Stéphane Mallarmé e ilustraciones de Edouard Manet.
} 
Para comprender el proceso de canonización de «El cuervo» en Europa hay que tener en cuenta, además, la publicación del poema con ilustraciones, litografía o grabados. José María Mesa Villar ${ }^{19}$ en su artículo sobre la influencia de Poe en Dante Gabriel Rossetti demuestra la admiración del artista prerrafaelita por el poeta inglés. Las ilustraciones que realizó para «The Raven» ${ }^{20}$ permitieron al artista prerrafaelista poner su imaginación al servicio de un programa estético propio que examinaba la relación entre la mente creativa y la trascendencia. En sus ilustraciones aparecen los dos ámbitos del poema: el real, representado por el estudiante obsesionado por la muerte de su amada, y el trascendente, ilustrado con seres fantasmagóricos con formas de mujeres o ángeles. Preside la escena el omnímodo cuervo.

Algunos años más tarde, en 1866, el poema se volvió a publicar en una antología británica con ilustraciones de John Tenniel ${ }^{21}$, el célebre ilustrador de Alicia en el país de las maravillas. El estudiante protagonista de sus ilustraciones es un joven airado, inquieto, de gran personalidad en su rostro. El cuervo está posado sobre el busto de Palas, proyectando su sombra sobre su figura. El ilustrador resalta la simbiosis entre la oscuridad y la claridad por su significado simbólico. En ninguna de las ilustraciones se alude al otro lado de la realidad.

Semejante comentario sugieren las ilustraciones que Edouard Manet realizó para Les Poème d'Edgar Poe (1888), la traducción llevada a cabo por Stéphane Mallarmé que ya hemos mencionado con anterioridad. Únicamente están presentes los tres sujetos materiales del poema: el poeta, el cuervo y el busto de Palas. Cierto es que el trazo de la plumilla es abierto, no completa la página y provoca cierta sugestión: parece como si las escenas fueran observadas por alguien desde el Más allá.

La écfrasis en la que mejor se percibe el tránsito de la misteriosa figuración romántica al evocador símbolo se elabora en famosos talleres de Gustave Doré en 1884. En todas las ilustraciones realizadas para esa edición están presentes los dos mundos: el de aquí y el de allá, el de la vida y el de la muerte, el del amante y el de la amada, la tumba y los ángeles... El cuervo, leit-motiv omnipresente en cada uno de los grabados, es el guardián de la puerta que impide ver qué hay Más allá, pero que da alas para alimentar la fantasía, la imaginación. Ya desde la primera ilustración contemplamos la figura del estudiante, de espaldas al lector, buscando entre las cortinas un pasadizo que le conduzca hasta su amada. La palabra «Nevermore» entra en la representación gráfica para acentuar la lectura ecfrástica del poema. El cuervo con su sombra revolotea bajo la imagen de un esqueleto. El camino de la interpretación queda abierto para que el lector ponga todo lo demás.

\footnotetext{
${ }^{19}$ J. M. Mesa Villar, «'Me atrajo su mirada tan suave como mi aliento’: La influencia de los aparecidos de Edgar Allan Poe en el perfil místico virginal de Dante Gabriel Rossetti», The Grove. Working Papers on English Studies, 16, (2009), pp. 129-150.

${ }^{20}$ Rossetti pintó seis ilustraciones para «Ulalume,» «The Sleeper,»y «The Raven». Véase H. Caine, Recollections of Dante Gabriel Rossetti, London, 1882. Estas ilustraciones inspiraron su obra «The Blessed Damozel». Se pueden ver dichas ilustraciones en Virginia Surtees, The Paintings and Drawings of Dante Gabriel Rossetti (1828-1882): A Catalogue Raisonne, London, 1971.

${ }^{21}$ En la British Library se puede consultar The Poetical Works of Edgar A. Poe, with Original Memoir, ilustrado por F. R. Pickersgill, J. Tenniel y Birket Foster, London, 1866.
} 


\section{LA APROPIACIÓN DEL SÍMBOLO: EL CUERVO EN LA POESÍA DE RUBÉN DARÍO}

Cristina Bravo Rozas ${ }^{22}$ demuestra la atracción que Rubén Darío sintió por lo sobrenatural, lo misterioso y su deseo de vislumbrar y aprehender ese espacio desconocido que hay Más allá de la vida. Resulta esclarecedora la primera nota publicada en su libro Los raros (1896) titulada «El arte del silencio» (García Sánchez, 1995) ${ }^{23}$. Se trata de un homenaje al libro de Camile Mauclair, L'Art en silence, en el que se inspira para escribir las semblanzas de aquellos artistas que sobrepasan los límites del tiempo, poetas que no necesitan hacer ruido para ser escuchados. Junto a Mallarme, Flaubert, Rodenbach, Puvis de Chavannes y Rops, destaca la presencia de Edgar A. Poe, encarnación de la «psicología de la desventura». Como le sucediera a Charles Baudelaire, Rubén Darío se reconoce en el alma de Edgar A. Poe, en su bohemia, en su desventurada y en su caótica vida. Marjorie Jonhston ${ }^{24}$ ha demostrado que Rubén Darío admiraba al poeta norteamericano tal y como se demuestra en Los raros (1896). Rubén Darío alaba la pasión de Edgar A. Poe por la belleza y la extraña filosofía de vida que revela en sus historias. A pesar de que en la biografia del escritor norteamericano hay bastantes puntos controvertidos, Darío destaca sus aspectos más favorables. Menciona las traducciones de Baudelaire, Mallarmé y Mauclair al francés. Parece claro que él se inspiraba en la biográfica Memoir que John H. Ingram (1842-1916) había escrito sobre Poe $^{25}$. Este crítico intentó salvar a Poe de la mala reputación a la que le había confinado R. W. Giswold ${ }^{26}$. Tanto la semblanza de Ingram como la edición de sus obras fue ampliamente difundida durante el siglo XIX. ${ }^{27}$ Sobre dicha influencia afirma Darío:

La influencia de Poe en el arte universal ha sido suficientemente honda y transcendente para que su nombre y su obra no sean a la continua recordados. [...] La obra de Ingram iluminó la vida del hombre; nada puede aumentar la gloria del soñador maravilloso. Por cierto que la publicación de aquel libro, cuya traducción a

${ }^{22}$ C. Bravo Rozas, «Los juegos terroríficos de Rubén Darío», Anales de Literatura Hispanoamericana 31, (2002), pp. 171-192.

${ }^{23}$ La primera edición de este libro se publicó en Buenos Aires en 1896. La segunda edición, española, aumentada y corregida vio la luz en Barcelona en 1905. Seguía, Rubén Darío, a su modo, la estela de otro clásico: Les poètes maudits de Paul Verlaine de 1884, cuya segunda edición, aumentada, data de 1888.

${ }^{24}$ M. Jonhston, «Rubén Dario’s Acquaintance with Poe», Hispania, 17, 3, (1934), pp. 271-278. Disponible la versión digital en: http://www.jstor.org/pss/331916 [2 de abril, 2013].

${ }^{25}$ E. A. Poe, The Poetical Works of Edgar A. Poe, with Original Memoir. London, 1866. Ilustraciones de F. R. Pickersgill, J. Tenniel y Birket Foster

${ }^{26}$ R. W. Griswold, The Poets and Poetry of America, Philadelphia, 1842. Edición disponible en formato digital: http://www.eapoe.org/papers/misc1827/1842ppa.htm [2 de abril, 2013].

${ }^{27}$ La edición de Ingram, The Works of the Edgar A. Poe, consta de cuatro volúmenes: volumen I: Tales, volumen II: Tales - Continuación, volumen III: Poems and Essays, including Eureka, Marginalia, etc., etc. volume IV: Autography, Criticism, and Index. Estos primeros volúmenes se publicaron mensualmente entre 1874-1875 y fueron reimpresos en 1880. Se puede consultar una edición del «Memoir» de Ingram en la siguiente dirección virtual: http://articles.poetryx.com/63/ [3 de marzo, 2013]. 
nuestra lengua hay que agradecer al Sr. Mayer estaba destinada al grueso público. ¿Es que en el número de los escogidos, de los aristócratas del espíritu no estaba ya pesado en su propio valor, el odioso fárrago del canino Griswold? La infame autopsia moral que se hizo del ilustre difunto debía tener esa bella protesta. Ha de ver ya el mundo libre de mancha al cisne inmaculado ${ }^{28}$.

Rubén Darío había leído con detenimiento la obra de Edgar A. Poe y estaba muy al tanto de las controversias que su vida y su literatura alentaban entre la crítica especializada. Por eso asume la responsabilidad de salvarlo de la ignominia y de la difamación a pesar de sus problemas vitales:

Nuestro Poeta, por su organización vigorosa y cultivada, pudo resistir esa terrible dolencia que un medio escritor llama con gran propiedad «la enfermedad del sueño». Era un sublime apasionado, un nervioso, uno de esos divinos semilocos necesarios para el progreso humano, lamentables cristos del arte, que por amor al eterno ideal tienen su calle de la amargura, sus espinas y su cruz ${ }^{29}$.

Destaca de él su ateísmo. Su alma estaba alejada del misticismo pero su necesidad de misterio le hacía producir tristísimos efectos que arrastraban al lector al borde de lo desconocido:

En todas sus obras, si mal no recuerdo, sólo unas dos veces está escrito el nombre Cristo. Profesaba, sí, la moral cristiana; y en cuanto a los destinos del hombre, creía en una ley divina, en un fallo inexorable. [...] No creía en lo sobrenatural, según confesión propia; pero afirmaba que Dios, como Creador de la Naturaleza, puede, si quiere, modificarla ${ }^{30}$.

La poesía de Poe es interpretada como panteísta. Darío se va identificando progresivamente con la personalidad del poeta muerto. Como en Poe, Dios para Darío no es más que una gran voluntad que penetra todas las cosas por la naturaleza de su intensidad.

A lo largo de toda la extensa semblanza que Rubén Darío dedica a Edgar A. Poe en Los raros se percibe la apropiación del mensaje del maestro. Todo poeta entabla una lucha edípica con las obras de sus predecesores. Rubén Darío no interpreta la tradición correctamente sino que construye una relectura deliberadamente incorrecta $-\mathrm{y}$, por tanto, creativa- de la vida y obra de Edgar A. Poe. La idea es interpretar a los grandes escritores del pasado como si hubiera un error en ellos o su propuesta estuviera incompleta, y convencerse de que él está corrigiendo su escritura. Lo que implícitamente hace todo escritor con la tradición literaria es releerla de tal modo que pueda marcar una diferencia. En el caso de Rubén Darío esa diferencia radica en la apropiación del

\footnotetext{
${ }^{28}$ R. Darío. Los raros. Zaragoza, 1998, p. 19.

${ }^{29}$ Ibidem, p. 15.

${ }^{30}$ Idem.
} 
talento e inspiración de Poe y recrea su vida y su obra mediante sus propias palabras, de manera que la fama del poeta norteamericano se asienta en los nuevos valores dominantes del simbolismo. Tanto Poe como Rubén salen reforzados.

Su primera visita a Nueva York en 1893 cuando regresaba a Nicaragua desde Madrid, donde había estado enviado por su Gobierno para cubrir la celebración del centenario del Descubrimiento de América ${ }^{31}$ le traspuso afectivamente al espacio real e imaginado de Edgar A. Poe. Fue en Nueva York donde conoció y se enamoró de una mujer cubana, Stella, a quien menciona junto a las amadas de Edgar A. Poe en la semblanza de Los Raros. En esa simbiosis de su amada platónica con las amadas literarias de Edgar A. Poe se percibe ese robustecimiento de la sublime herencia del poeta norteamericano ${ }^{32}$. Refiriéndose a ellas aparece, por primera vez, su apropiación del cuervo:

Ellas son, cándido coro de ideales oceánidos, quienes consuelan y enjugan la frente al lírico Prometeo amarrado a la montaña Yankee, cuyo cuervo, más cruel aún que el buite esquiliano, sentado sobre el busto de Palas, tortura el corazón del desdichado, apuñaleándole con la monótona palabra de la desesperanza ${ }^{33}$.

Rubén Darío compara, instintivamente, el cuervo de Poe con el buitre de Prometeo porque, dado su conocimiento de la mitología clásica, es su referencia cultural inmediata. Edgar A. Poe es el nuevo Prometeo, quien por difundir conocimiento poético a sus semejantes, será torturado por un cuervo que le carcome el corazón ${ }^{34}$.

\section{DE LA APROPIACIÓN SIMBÓLICA AL DESVÍO ESTÉTICO: LA DISEMINACIÓN DEL SÍMBOLO EN LA POESÍA MODERNISTA ESPAÑOLA}

¿Cómo se intuye, se entiende y transmite el símbolo ‘cuervo' en la poesía española? ${ }^{35}$. El poema fue traducido y publicado en varias ocasiones durante el siglo XIX de manera autónoma unas veces, o formando parte de volúmenes colectivos. Como

\footnotetext{
31 E. G. Fay, «Rubén Darío in New York», Modern Languages Notes, 57, 8, (1942), pp. 641-648.

32 E. A. Poe, Poemas, Montevideo, 1919. Ed. de Rubén Darío.

33 R. Darío, Los raros, Zaragoza, 1998, p. 16.

${ }^{34}$ Más adelante se hará referencia al poema «El buitre» de Miguel de Unamuno en el que el yo lírico se identifica con Prometeo y su afán de conocimiento le irá devorando sus entrañas.

${ }^{35}$ La recepción de la obra de Edgar A. Poe en la literatura hispanoamericana está bien estudiada en la obra de J. E. Englekirk, Edgar A. Poe in Hispanic Literature, New York, 1934. Su tesis sostiene que la obra del Poe poeta se transfirió a los poetas románticos y modernistas latinoamericanos bien en versión original o en traducción. Más reciente es la tesis doctoral de S. Rodríguez Guerrero-Strachan, Presencia de Edgar Allan Poe en la literatura española del siglo XIX, Valladolid, 1999, que se centra en las narraciones de Poe y su influencia en novelistas como Pedro Antonio de Alarcón (1833-1891), Emilia Pardo Bazán (1851-1921) y Gustavo Adolfo Bécquer (1836-1870). Hay alusiones tanto en la obra de Englekirk como en la de Rodríguez Guerrero a la huella poética del norteamericano en general, pero no se estudia con el cuervo como símbolo, solo como motivo estético que pasa de unos a otros. La primera obra de Poe que se conoció en España fue
} 
Agustín Aguilar y Francisco Ortega afirmaban en la mencionada introducción: «aparte de 'El Cuervo', la más celebre de sus obras poéticas..., son muy pocas las que en nuestro idioma conocemos $»^{36}$.

Si bien la influencia del Poe prosista deriva de la traducción francesa, su obra poética es conocida gracias a las traducciones del inglés que se elaboraron en Hispanoamérica. No se debe olvidar el influjo que debió suponer el hecho de que Rubén Darío pusiera en primer término de Los raros la semblanza del poeta norteamericano. En el ejemplar Joyas poéticas americanas. Colección de poesías escogidas. Originales de autores nacidos en América, selección hecha por Carlos Romagosa ${ }^{37}$ que custodia la Biblioteca Nacional de España se recopilan poetas americanos del norte, del centro y del sur en cuatro idiomas originales, castellano, inglés, portugués y francés. Presiden la antología dos poemas de Edgar Allan Poe, «The Raven» y «The Bells» en versión original primero y posteriormente se consignan las traducciones, llevadas a cabo por Juan Antonio Pérez Bonalde y por Domingo Estrada ${ }^{38}$. Se publican a continuación una vasta antología de poemas. Carlos Romagosa pretende ofrecer una selección de poesía 'americana' para hispanohablantes. En la introducción se aclara que estos poetas están llevando a cabo en América semejante revolución a la acaecida en Francia en el año 1883 cuando estalló la cruzada del simbolismo representado por Jean Moreas, Laurent Tailhade y Paul Verlaine ${ }^{39}$.

Atentos estaban en España a lo que se estaba fraguando poéticamente tanto en Francia como en América. La primera alusión aparece en Manuel Reina Montilla (1856-

Historias extraordinarias. En 1858, Pedro Antonio de Alarcón publica «Edgar A. Poe. Carta a un amigo» en La Época. En esta carta señala que diez o doce copias de Histoires extraordinaires, la traducción al francés llevada a cabo por Baudelaire, estaban en circulación desde el año anterior (1857). Las Historias extraordinarias circularon, pues, en España en la traducción francesa, realizada por Baudelaire en 1856 (Rodríguez Guerrero, 1999: 14). Desde esa fecha hasta que Agustín Aguilar y Francisco Ortega en la introducción a su traducción de Poesias comentan: «pocos autores extranjeros son tan conocidos y apreciados en España como Edgar A. Poe» (1930: 12) ha trascurrido casi un siglo. Alejandro Sawa («Crónica literaria (Poe y Baudelaire)». El Cojo Ilustrado, 12, 15 de octubre, (1903), p. 608), Emilio Carrere («Edgar Poe, ocultista», Las ventanas del misterio, Madrid, s.a. pp.37-42), Mauricio Dumolin («Edgardo Poe, autor y marido», La Revista Blanca, 7, 15 de agosto, 1904), Juan de Sola («Heráldica (Poe y Baudelaire)», El Cojo Ilustrado, 14, 1 de febrero, 1905), Ocoa F. Salcedo («Edgar A. Poe (Una visita a su tumba)», El Cojo Ilustrado, 14, 15 de marzo, (1905), pp. 200-202) y una larga retahíla de escritores dedican palabras de homenaje al poeta y al hombre.

${ }^{36}$ E. A. Poe, Poesías, Cádiz, 1930, p. 6. Traducción de Agustín Aguilar y Tejera y Francisco R. Ortega y Frías.

${ }^{37}$ C. Romagosa, Joyas poéticas americanas. Colección de poesías escogidas originales de autores nacidos en América, Córdoba, República Argentina, 1897.

${ }^{38}$ P. Carrascosa y J. M. Zarandona, «Una traducción hispanoamericana de 'The Raven', de E. A. Poe: “El cuervo", de José Antonio Pérez Bonalde», Babel afial. Aspectos de Filología Inglesa y Alemana, 3-5, (1996), pp. 213-228.

${ }^{39}$ Buena parte de los poemas seleccionados tienen influencia de «The Raven» de Poe. Cuervos aparecen en el poema del argentino Leopoldo Díaz «Castalia Bárbara», de los mexicanos Salvador Díaz Mirón «Víctor Hugo» y Manuel Gutiérrez Nájera «Tristissima Nox», del cubano Julián del Casal «Pax Animae», del argentino Olegario V. Andrade «Prometeo» y del centroamericano Rubén Darío en su «Responso a Verlaine» y «Coloquio de los Centauros» -justo se seleccionan los dos en los que aparecen precisamente cuervos. Los poemas antologados lo son en virtud del gusto del editor por lo narrativo y por su sensibilidad hacia el decadentismo y el nuevo ritmo poético. 
1905), poeta posromántico, a quien Juan Ramón Jiménez definió como «parnasiano impecable» ${ }^{40}$ y vio en él al Gautier español por su búsqueda de la belleza a través de los gustos clásicos. El poeta cordobés evoluciona desde el estilo romántico de $\mathrm{An}$ dantes y allegros (1877) al premodernismo de Cromos y acuarelas (1878). En La vida inquieta (1894) se revela un poeta maduro, influido por los simbolistas franceses y de Edgar A. Poe. La vida inquieta se publicó dos años antes de que Prosas Profanas (1896) y celebra todos los motivos de la bohemia modernista. «La última noche de Edgardo Poe» es un canto homenaje al poeta norteamericano. Edgardo Poe yace muerto a las puertas de la taberna. Los versos finales rezan: «iSobre el cuerpo del mísero Edgardo / revolaba aquel cuervo fatídico / de su triste, / espantable poema, / dando roncos y fúnebres gritos! $\rangle^{41}$. El cuervo abre la puerta a la muerte fatídica, parodiado por esos roncos y fúnebres gritos. Manuel Reina revive la imagen antisocial y ebria que Baudelaire había divulgado.

El graznido del cuervo no le pasó desapercibido a Antonio Machado (1875-1939). En la edición de Soledades (1903) ${ }^{42}$ publica dos poemas titulados «Mai piú» y «Nevermore ${ }^{43}$. La mayoría de los poemas que completan el volumen fueron compuestos entre 1899 y 1902, coincidiendo con las frecuentes reuniones de jóvenes modernistas en casa de Rubén Darío y con su estancia en París. La influencia de Edgar A. Poe en Antonio Machado ha dado lugar a la publicación de varios artículos ${ }^{44}$. La clave más fiable para justificar la influencia la ofrecen los propios textos. «Nevermore» describe la visita que le hace al poeta el «iEspíritu de ayer!» durante una «tarde vieja en el alma». La atmósfera de los hechos podría estar inspirada en «El cuervo» ${ }^{45}$.

\footnotetext{
${ }^{40}$ J. R. Jiménez, Antolojía jeneral en prosa, Madrid, 1981, p. 781.

${ }^{41}$ M. Reina, La vida inquieta. Exeter, 1978. Edición de Richard Cardwell.

${ }^{42}$ A. Machado, Soledades -1903-, Exeter, 2006. Edición de Dolores Romero López.

${ }^{43}$ El poema se publicó antes en la revista Electra 1901 y con seudónimo. Dos años más tarde y en la misma revista se publica la traducción al castellano de «The Raven» en traducción de V. Díaz-Pérez.

44 Tomás Labrador Gutiérrez («Presencia de Edgar A. Poe en Antonio Machado», Archivo Hispalense, 157, (1974), pp. 87-119; y en «Variaciones en torno a 'El cuervo' de Poe», Espéculo. Revista de Estudios Literarios 20, (2002) pp. 55-683), Olivia Areti («Antonio Machado e la poetica di E. A. Poe», Studi Ispanici, (1979), pp. 131-140) e Yndurain («Machadiana: notas de lectura», Boletín de la Biblioteca Menéndez Pelayo, 55, (1979), pp. 189-205) indagan sobre la influencia de las teorías poéticas de Poe en Antonio Machado. Eugene del Vecchio («E. A. Poe and Antonio Machado: An Undetected Affinity», Discurso Literario 5, 2,(1988), pp. 395-400), José Antonio Gurpegui («Poe in Spain», Poe Abroad. Influence, Reputation, Affinities, ed. L. Davis Vines, Iowa, (1999), pp.108-115) y Amparo Gutiérrez («Poe in Spain», Poe Abroad. Influence, Reputation, Affinities, ed. L. Davis Vines, Iowa, (1999), pp.108-115) plantean de manera general sus afinidades. Mercedes Gutiérrez García («El ‘cuervo’ de E. A. Poe en 'Nevermore’ y ‘Mai piú’, dos poemas de Antonio Machado», Crítica Hispánica 1-2, (2008), pp. 55-68) y Cristina Flores Moreno («iAyer es nunca jamás! Recepción e influencia de la poesía de Edgar A. Poe en Antonio Machado», Odisea: Revista de estudios ingleses, 10, (2009), pp. 83-96) profundizan en la influencia cuestionando las posibles vías por las que Machado habría podido llegar a conocer la obra poética del norteamericano. Es posible, como apuntan unos y otros, que su fuente de información fueran las consabidas traducciones francesas de Baudelaire y Mallarmé y no creo, como Tomás Labrador Gutiérrez sugiere, que Antonio Machado leyera el original en

${ }^{45}$ Como ejemplos: «la cortina de la alcoba», «el silencio turbio de un espejo» y un eco que responde: «Un nunca más, que dolorido plañe!». La imposibilidad de recuperar el pasado es igualmente el tema central alrededor del que se construye «Mai piu» - traducción italiana de nevermore - con los recursos propios de la
} inglés. 
Tanto en «Nevermore» como en «Mai Piú» el protagonista es el pobre poeta desencantado que espera una grotesca ilusión, una alegría y lo que escucha es un eco dolorido que le responde un nunca más. Al poeta no le queda posibilidad alguna de salvación. Machado, siguiendo la estela de Poe, se vale de la concatenación de los versos para acrecentar la fatalidad del momento. Los protagonistas de estos tres poemas «Nevermore», «Mai piu» $\mathrm{y}$ «El cuervo» están condenados a deambular con su tragedia por la vida. La concepción de la amada es similar: joven virginal, escurridiza, una visión a la que se les ha denegado el acceso, un ensueño. Poe se adentra en la psique para explorar lo supersticioso y lo terrorífico, mientras que Machado, más preocupado por la desaparición de la memoria y el sueño, desarrolla imágenes y motivos que sirven para reproducir su desasosiego ${ }^{46}$. Hay otro detalle que resulta significativo en el análisis de la evolución del cuervo como símbolo y es que en Antonio Machado el pájaro que roza su ventana es una «golondrina». Las golondrinas eran pájaros más afines a la cultura (Bécquer, como ejemplo) y a la vida españolas que los cuervos y Machado lo siente así y así lo expresa adaptando primorosamente su escritura a su vivencia. Años más tarde en su «Poética» (1931) propuso al poeta norteamericano como uno de los padres de la poesía moderna y, sin duda, lo fue, pero cada poeta acepta la influencia adaptándola a su propia idiosincrasia.

Francisco de Villaespesa en «La elegía de las campanas» ${ }^{47}$ asocia, como Machado, el sonido de las campanas y la muerte de aquellos que se fueron y no volverán. La ambientación del poema recuerda con fidelidad al de Poe: un ruido le despierta y le hace saltar de la cama, el viento apaga la tímida lámpara que tiene encendida. El yo lírico tiembla con pavor, se le erizan los cabellos. Siente que alguien se acerca hasta su lecho. Huele a sepultura. Se le acerca la muerte. Semejante atmósfera recorre los versos de El libro del amor y de la muerte ${ }^{48}$ donde leemos: «En la paz de este bosque taciturno / un obscuro pavor la noche exhala, / y nos roza el presagio, como el ala / agorera de un pájaro nocturno./ ¡Nunca, nunca, su paso fugitivo / alegrará el silencio de la casa!... / ¡Nunca más!... ¡ ¡Nunca más!... cierra la puerta, / apaga el fuego del hogar, la lámpara». Ese pájaro nocturno se convierte en murciélago que se alimentan con los lívidos gusanos que devoran a las vírgenes en uno de los poemas de Mis mejores poesías ${ }^{49}$. Reconocemos el influjo de «El cuervo» al leer: «Los fulgores de la lámpa-

tópica modernista (Vid. D. Romero López, Una relectura del Fin de Siglo en el marco de la Literatura Comparada, Berna, 1998): Una mañana de abril el poeta abre su ventana y entra el canto de las alondras y el sonido de la fuente y el perfume de las flores. Después llega la tarde melancólica y el viento trae perfume de rosas y doblar de campanas. Entonces se recurre al tópico del Ubi sunt y el poeta pregunta «¿Dónde están los huertos floridos de rosas?» La tarde de abril le responde que la alegría había llamado a su puerta y no volverá a llamar otra vez. El poeta establece un contraste entre la intensa felicidad experimentada durante la mañana de un día de abril, y la tristeza que le inunda cuando, al caer la tarde, se hace patente que el momento previo de dicha ya no volverá: «La alegría / pasó por tu puerta (...) / Pasó por tu puerta. Dos veces no pasa».

${ }^{46}$ E. del Vecchio, «E. A. Poe and Antonio Machado: An Undetected Affinity», Discurso Literario, 5, 2, (1988), pp. 395-400.

${ }^{47}$ F. de Villaespesa, In memoriam, Madrid, 1910.

${ }^{48}$ F. de Villaespesa, Libro del amor y de la muerte, Barcelona, 1928, p. 66.

${ }^{49}$ F. de Villaespesa, Sus mejores versos, Madrid, 1929. 
ra morían / Y turbaban el silencio / De mi alcoba solitaria los medrosos aletazos / De un fatídico murciélago» ${ }^{50}$. Nuevamente se repite un desvío del símbolo hacia un motivo modernista: a Francisco Villaespesa le parece más lógico que mencionar un murciélago en la solitaria noche. Con este significativo giro marca su personal diferencia con el maestro.

Indagando en la obra de Emilio Carrere (1881-1947) se encuentra algún poema inspirado en el misterioso y canalla cuervo ${ }^{51}$. El homenaje poético se lo rinde a Edgar A. Poe en El caballero de la muerte ${ }^{52}$ con los poemas «Nulla est redemptio» $»^{53}$, «Tristeza granate» ${ }^{54}$, «La bella locura»y «Horas». En este último el poeta asume la personalidad funesta de Edgar A. Poe y exclama: «Soy el bardo maldito. / En el altar del Mal tengo mi rito; / Mi única y triste amiga, la corneja, / Al pasar me saluda con su grito / Desde su nido de la torre vieja». El poeta se transforma en el mismísimo Edgardo Poe, un personaje de ultratumba que trata de penetrar en los hogares felices. Su lugar natural es la ciudad maldita donde se escucha el tañido de la campana que inexorablemente da las horas: «Cual llanto de metal, del campanario / Caen las horas.... Las horas.... La agorera / Corneja chilla. Mi alma nada espera. / ¡Ay de mi vida; en el funesto horario, / cuándo caerá la lágrima postrera!». El poema de Emilio Carrere es más narrativo que el de Antonio Machado. Pero la idea es la misma: la frustración porque el tiempo pasa y no se llega a alcanzar lo que se espera de la vida. Al igual que en Machado, el cuervo sufre una transformación. Ahora es la «corneja» la que entona un tempus fugit.

El joven y sensible Juan Ramón Jiménez se debió reconocer en el semblante elegante y la misteriosa alma de Poe. El poeta de Moguer confesó sin reservas su admiración por Poe ${ }^{55}$ y comentó en numerosas ocasiones la influencia de éste sobre su pro-

\footnotetext{
${ }^{50}$ F. de Villaespesa, Sus mejores versos, Madrid, 1929, p.15.

${ }^{51}$ Julia Labrador Ben y Alberto Sánchez Álvarez-Insúa han llevado a cabo una revisión exhaustiva de la obra del madrileño, con especial atención a sus libros Románticas (1902) y El caballero de la muerte (1909). Véanse J. Ma Labrador Ben y A. Sánchez Álvarez-Insúa, «La obra poética de Emilio Carrere (I). Emilio Carrere y sus poemarios Románticas y El Caballero de la Muerte», Dicenda, Cuadernos de Filología Hispánica, 19, (2002), pp. 115-145 y J. M Labrador Ben, «Emilio Carrere y el ocultismo», Bohemios, raros y olvidados, ed. Antonio Cruz Casado, Córdoba, pp. 669-699. Emilio Carrere es no solo poeta, sino también novelista, periodista, crítico literario, disertador y traductor. Llevó a cabo la traducción de Poemas saturnianos y Canciones para ella de Paul Verlaine y La mano embrujada y Aurelia de Gérard de Nerval. Tradujo del original francés de Charles Baudelaire las Historias extraordinarias de Poe publicadas sin año de edición en la Colección de Autores Célebres Extranjeros. En su «Nota Preliminar» a la antología del modernismo hispánico La corte de los poetas (1906) Emilio Carrere ensalza la figura de Rubén Darío como vate, gracias al cual ha resurgido una juventud aristocrática en España, llena de ideales estéticos.

${ }^{52}$ E. Carrere, El caballero de la muerte, Madrid, 1909.

${ }^{53}$ Una sombra virginal llama a su corazón, pero éste no se despierta, llegan tarde a su vida. Y al final el yo lírico exclama: «En vano, sombra clemente, / Tus sueños me ofrecerás, / Yo sufriré eternamente, / Llevo un letrero en la frente / Que dice: ¡Jamás! ¡Jamás!». El tono poético es semejante al que antes hemos mencionado en el análisis de Antonio Machado.

${ }^{54}$ En este poema se hace expresa referencia al cuervo: «Mucho también yo he llorado; / Esclavo fui del acerbo / Odio y la roja pasión. / Cuando miro hacia el pasado, / Hunde un fatídico cuervo / Su pico en mi corazón».

${ }^{55}$ S. González Ródena, Juan Ramón Jiménez a través de su biblioteca. Lectura y traducciones de la lengua francesa e inglesa (1881-1936), Universidad de Sevilla, 2005.
} 
pia obra ${ }^{56}$. Pese a que el poeta maduro, el que reflexiona sobre su pasado, dice haber leído a Poe desde joven, lo cierto es que no se hallan reminiscencias de «El cuervo» hasta Laberinto, compuesto en 1910 y publicado en 1913 donde aparecen una de las «Memorias tristes» titulada «Nevermore». Sugestiva cita se encuentra en uno de los poemas de Domingo, compuesto entre 1911-1912 y publicado póstumamente: «Negro, perdido pájaro, mi súbita nostaljia, / Ciega de sangre, entra por - ioh muerta esperanza!- / Un cristal roto, y sale por otro, a la azul nada...» Nótese como el cuervo queda convertido en un simple «perdido pájaro», que entra por el cristal roto y sale por otro. En Diario de un poeta recién casado (1916) parecen tres referencias al cuervo $^{57}$. En 1922, cuando publica «Tenebrae» en su Segunda antolojía poética. Nuevamente pinta un ocaso amarillo por el que cruzan «bandadas negras de pájaros melancólicos» y al poeta le zumba en los oídos una retahíla que no sabe de donde viene y «que dice: «Nunca... Nunca...»

Miguel de Unamuno se acercó a la obra de Poe desde la erudita postura de un académico universitario ${ }^{58}$. Como lector de literatura inglesa, sintió siempre gran interés por el periodo romántico tal y como comprobar por el número de obras que contiene su biblioteca personal ${ }^{59}$. El 19 de agosto de 1923 Unamuno publicó en La Nación de Buenos Aires un pequeño ensayo titulado «La moralidad artística» donde se comentaba el libro de John Robert Robertson Edgar A. Poe: A Psychopathic Study (1923). Unamuno defiende a Poe contra las críticas que había venido recibiendo a lo largo de los años basadas en su persona. Unamuno defiende la calidad estética de su trabajo ${ }^{60}$. Se encuentra

\footnotetext{
${ }^{56}$ Carmen Pérez Romero lo cita reconociendo que: «Desde 1900 influyen en mi Rubén Darío... Baudelaire, Mallarmé (con sus poemas originales en prosa y sus magníficas traducciones de Poe que leí antes que las de Baudelaire». Véase la cita en C. Pérez Romero, Juan Ramón Jiménez y la poesía anglosajona, Cáceres, 1981, p. 143.

${ }^{57}$ La primera es una alusión apocalíptica en el poema que dedica a Enrique y Amparo Granados que perecieron ahogados cuando el Sussex, barco inglés en que regresaban a España, fue torpedeado por los alemanes en 1916 durante la Primera Guerra Mundial. La segunda en el poema CXXXII escrito el 7 de mayo en Nueva York que dice así: «¿El cielo? Un incoloro color más, para hacer, en franjas iguales, una bandera -enseña de lo mortalcon la cortina azul a un tercio de ventana y, a dos tercios, la cortina amarilla. El cuervo dice: Nada más». El Diario es un libro de viaje el que el poeta abre, por primera vez, su corazón al amor y al mundo real. Aún así, ese cielo que contempla desde el barco es color azul, pero enseguida transfiera el significado real al simbólico y ve en él una cortina amarilla que tiñe de muerte sus ilusiones. La tercera alusión que aparece en Diario lleva nombre propio. Se trata del «La casa de Poe». Juan Ramón Jiménez al llegar a Nueva York busca la casa donde vivió el mito. Sabemos que Poe vivió en tres ocasiones en la ciudad de Nueva York, una vez en 1837 y otra en 1838 y después desde 1844 hasta su muerte en 1849. Juan Ramón Jiménez busca una casa chiquita, blanca.... casi como una casa andaluza. Pregunta a unos jóvenes, pero no se saben dónde está. Pregunta a una viejita, pero ya no le queda memoria para recordar el sitio exacto. Así que el poeta imagina la casa iluminada por la luna y cubierta de impoluta nieve. Véase J. R. Jiménez, Diario de un poeta recién casado, Madrid, 1998.

58 Th. Franz, «Unamuno and Poe / Valery Legacy», Revista Hispánica Moderna, 1, (1997) pp. 48-56.

${ }^{59} \mathrm{Su}$ biblioteca también alberga una traducción al francés de «The Raven», una biografía de Poe y una obra crítica sobre la presencia de E. A. Poe en la poesía francesa. La colección de poemas en inglés está profusamente anotada con marcas en los márgenes, lo que indica su atenta lectura. En ella, según información que facilitan Thoman Inge y Gloria Dowling, (1970) se encuentran varios volúmenes: la edición de John H. Ingram de Tales of Edgar A. Poe, de 1907 y la Andrew Lang The Poems of Edgar A. Poe with a Selection of Essays, de 1927.

${ }^{60}$ J. R. Canto Nieto, «El mito de Prometeo en la poesía y en la filosofía de Miguel de Unamuno», Cuadernos de Filología Clásica. Estudios Griegos e Indoeuropeos 16 (2006), pp. 283-305.
} 
alguna referencia al cuervo en Cancionero, conjunto de poemas escritos entre 1928 y 1936 y que se publicó por primera vez en $1953^{61}$ : «Edgar Poe, aquel tu cuervo / Nevermore -todo un loro- / Edgar Poe, todo tu oro / - escarabajo- es el verbo». El collage de palabras sacadas de contexto y abrazadas bajo una fuerte rima consonante no permite que se hable de símbolo. Este cuervo es un motivo paródico convertido ahora en 'loro' debido a su locuacidad. No es este el ejemplo que más nos interesa ${ }^{62}$.

\section{CONCLUSIONES}

La investigación podría hacerse más prolija en ejemplos pero la tesis queda ya suficientemente demostrada ${ }^{63}$. El cuervo como mensajero y símbolo del más allá obtuvo un éxito notable durante el Romanticismo norteamericano porque representaba la muerte, el misterio y lo oculto. La desorientada vida de Edgar A. Poe y su temprana muerte fue interpretada por Charles Baudelaire como si de un mito poético se tratara y consagró como prototipo del hombre bohemio. Rubén Darío une el símbolo poético al nefasto final del poeta en «Responso a Verlaine» y al utilizar el pájaro protervo en su poema engrandece el mito. Los demás modernistas tendrán el camino abierto para su recreación gracias a la influencia de Darío y a las conversaciones que mantuvieron en su casa cuando el poeta americano residió en Madrid en 1899. El cuervo sigue manteniendo su significado como emblema del más allá; el yo lírico asume la fatídica identidad del bohemio pero el símbolo se disemina y se dispersa en motivos estéticos más acordes con la vida cotidiana y cultural de España: el murciélago, la golondrina, la corneja o el funesto pájaro. Ocultismo religioso y antropológico enriquecen el significado simbólico del fatídico pájaro; pero, en su trayectoria, se va despojando de sus valores originarios y se adentra en la tópica poética.

${ }^{61}$ M. Th. Inge, «Miguel de Unamuno's Canciones on American Literature» Arlington Quarterly 2, (1969), pp. 83-97. Véase M. de Unamuno, Cancionero. Diario poético, Buenos Aires, 1953 y también M. de Unamuno, (1966), Obras Completas, Madrid, 1966.

${ }^{62}$ Podríamos sentir tentación de apuntar una influencia de Poe en el buitre de Unamuno pero podríamos confirmarla. El buitre de Unamuno, al que dedica la extensa composición «El buitre de Prometeo» (Poesías, 1907) y el soneto «A mi buitre» (Rosario de sonetos líricos 1911) proviene de su conocimiento del mito de Prometeo en la tradición clásica. Unamuno se identifica con Prometeo y se convierte en un mártir de su conciencia por no poder alcanzar la inmortalidad ya que el buitre también morirá cuando le devore a él completamente.

${ }^{63}$ La lista de poetas podría continuar: desde Gregorio Martínez Sierra (1881-1947) en Renacimiento (1907) donde expresa su admiración por Heine, Poe y Verlaine, a Manuel Machado (1874-1947) en La guerra literaria (1913) que suma a la nómina nuestro Bécquer (1967) o el bohemio Alejandro Sawa (1862-1909) que menciona a Edgar A. Poe como uno más dentro del panorama cultural hispánico en sus Crónicas de la bohemia, Madrid, 2008. Estudio preliminar de Iris M. Zavala. Edición, introducción y notas de Emilio Chavarría. 